\title{
Urgences
}

\section{Alfred Döblin : Hamlet ou la Longue Nuit prend fin, traduit de l'allemand par Élisabeth et René Wintzen, Paris, Fayard, coll. " Littérature étrangère ", 1988, 498 p.}

\section{Renald Bérubé}

Numéro 21, novembre 1988

Bagatelles et crases

URI : https://id.erudit.org/iderudit/025499ar

DOI : https://doi.org/10.7202/025499ar

Aller au sommaire du numéro

Éditeur(s)

Urgences

ISSN

0226-9554 (imprimé)

1927-3924 (numérique)

Découvrir la revue

Citer ce compte rendu

Bérubé, R. (1988). Compte rendu de [Alfred Döblin : Hamlet ou la Longue Nuit prend fin, traduit de l'allemand par Élisabeth et René Wintzen, Paris, Fayard, coll. " Littérature étrangère ", 1988, 498 p.] Urgences, (21), 109-110.

https://doi.org/10.7202/025499ar d'utilisation que vous pouvez consulter en ligne.

https://apropos.erudit.org/fr/usagers/politique-dutilisation/ 


\section{deliveline}

\section{Alfred Döblin: Hamlet ou la Longue Nuit prend fin, traduit de l'allemand par Elisa- beth et René Wintzen, Paris, Fayard, coll. "Littérature étran- gère», 1988, 498 p.}

J'ai l'impression d'être comme Hamlet auquel on ment, que l'on veut distraire et envoyer finalement en voyage - parce qu'on le craint, parce qu'il sait ce qui s'est passé.

Alfred Döblin, Hamlet ou..., p. 183.

Les énoncés ne sont plus considérés exclusivement par rapport aux réalités qu'ils désignent mais aussi en tant que porteurs de voix. Dans la production de son oeuvre, le poète partira souvent d'une phrase dans laquelle il retiendra non le sens, mais les échos d'énonciations antérieures.

Tzvetan Todorov, Critique de la critique $^{1}$

La première phrase du roman, sobre et laconique, brève: "On le rapatria». Et le prétexte original de ce gros roman apparaît simple aussi: à la fin de la Deuxième Guerre mondiale, Edward Allison, amputé de sa jambe gauche et gravement traumatisé - attaqué par deux avions-suicides japonais, le croiseur qui le menait vers le continent asiatique a entièrement brûlé -, est rapatrié dans son Angleterre natale. Commence alors une longue convalescence qui, sur l'insistance de sa mère Alice, se déroulera dans la maison familiale, sous le re- gard inquiet et attentif du docteur King, vieil ami de la famille. Sous le regard du père également, Gordon Allison, écrivain de son métier, appelé aussi lord Crenshaw d'après le sujet de l'une de ses "premières histoires» (p. 39):

\section{Gordon comprit lentement qu'Edward avait une thèse: certaines personnes portaient la responsabilité de la guerre et de son malheur. Il fallait donc découvrir les personnes qui étaient responsables de la bou- cherie collective et du malheur ( $\mathrm{p}$. 33).}

Mieux valant, du point de vue de l'écrivain, raconter que discuter (p. 36), Gordon Allison suggère, pour aider à la guérison de son fils, que parents et amis se réunissent et racontent des histoires. $\mathrm{Ce}$ qui sera fait, composant le roman que nous lisons.

La guérison, c'est-à-dire le rapatriement ultime du fils traumatisé; au coeur de sa longue nuit, Edward Allison, nouvel Hamlet à la fois naîf et méfiant, entendra (s'inventera aussi) mille et un récits - quire-racontent, par exemple, les légendes gréco-latines et judéochrétiennes de Médée et de Salomé, celle des cours d'amour médiévales, du roi Lear ou de Michel-Ange ${ }^{2}$. On aura compris que, dans ce roman de Döblin, l'intertextualité fonctionne à plein régime: le Hamlet du titre affichait déjà un pacte, pacte qui se trouve encore élargi ou investi d'une puissance accrue quand le lecteur ou la lectrice doit constater que "la longue nuit" ressortit aussi aux Mille et une. Dès le début du roman, à l'occasion d'une discussion entre lord Crenshaw et sa fille Kathleen, le mot palimpseste, sans être prononcé, avait d'ailleurs été défini: «... un récit qui 
a traversé les siècles et qui, au cours de cet itinéraire, a été retouché comme un vieux tableau authentique, recouvert de laque et de vernis, au point qu'il est difficile d'accéder à l'original» (p. 45).

La lecture du Hamlet de Döblin, dès lors, doit suivre simultanément plusieurs pistes: comment entendre et lire, compte tenu de la situation de la narratrice et du dédale de ses relations avec les divers auditeurs, le récit des aventures de Théodora ou de Proserpine selon Alice? Et comment entendre et lire les interprétations de ces récits selon Edward, compte tenu de tout cela et du fait aussi que nous (re)lisons Hamlet? Quand un narrateur ou une narratrice prend la parole, ses énoncés renvoient à des voix multiples que les voies de lecture doivent toutes prendre en compte la polyphonie est bien une soeur jumelle de l'intertextualité et du palimpseste. Et le bref essai de Todorov, dont nous avons cité quelques lignes en épigraphe, montre bien que Döblin, dès la fin des années 20 , avait sciemment établi la théorie de son écriture romanesque. A l'image même de son hypotexte en cinq actes, le Hamlet en cinq parties de Döblin est une inépuisable merveille, tout à la fois un merveilleux roman et un art romanesque subtilement tissé. Le plaisir de lecture, ici, n'est jamais pris en défaut - l'intelligence et la sensibilité y sont également et particulièrement bien servies.
Né en 1878 à Stettin, ville allemande alors, Alfred Döblin fait partie de cette génération d'écrivains, d'artistes et d'intellectuels qui firent, furent et sont l'honneur de l'esprit allemand face à la montée du nazisme. La renommée lui vint avec Berlin Alexanderplatz, roman publié en 1929. D'origine juive et médecin de formation, Döblin dut s'exiler en 1933; commencé à Hollywood en 1945 et terminé à Baden-Baden en 1946, son Hamlet, fort controversé, ne fut publié qu'en 1956, en Allemagne de l'Est. Presque oublié littérairement, Döblin devait mourir l'année suivante, le 26 juin 1957, quelque temps avant la publication de son roman dans l'Allemagne de l'Ouest qu'il habitait. Ulysse le sait mieux que quiconque et Hamlet s'en doute bien: les rapatriements sont toujours des odyssées d'au moins mille et une nuits, peuplées de mille et une apparitions.

\section{Renald Bērubé}

1. Tzuetan Todorov, Critique de la critique. Un roman d'apprentissage, Paris, Seuil, coll. «Poétique», $1984, p .44$. Le chapitre où figurent ces lignes s'intitule ale Retour de l'épique (Döblin et Brecht)».

2. En tout, wa cycle of eleven autonomous stories set within a narrative framex, ecrit A. W. Riley (p. 133) qui ctudie la genèse de l'une de ces onze histoires, celle du troubadour Jaufré Rudel (*daufré Rudel in Alfred Döblin's Last Novel, Hamlet *, Mosaic, Winnipeg, vol. X, no 2, 1977, p. 131-145). 